\title{
46
}

\section{The Legal Roots of a Sustainable and Resilient Economy: New Kinds of Legal Entities, New Kinds of Lawyers?}

\section{Bronwen Morgan, ${ }^{1}$ Joanne McNeill² and Isobel Blomfield ${ }^{3}$}

This chapter seeks to persuade professional lawyers and ecologicallyminded social entrepreneurs that a significant gap in legal professional services currently exists in the ecosystem of support for small-scale sustainable economy initiatives. The chapter has four parts. Part I makes a general case for the proposition that legal reforms facilitating the growth of small-scale sustainable economy initiatives (SSEIs) are an important dimension of facilitative environmental law. Part II identifies existing patterns of support. Part III draws on the limitations of these existing patterns, when understood in the context of the distinctive needs of SSEIs, to sketch an outline of four possible responses to this gap. These are: cultivating a vital yet elusive sense of what we call 'the touch'; introducing novel hybrid legal forms for the conduct of SSEI activity; developing and adapting specific technical skill sets to the SSEI context; and improving the cost, accessibility and relevance of legal support.

Faculty of Law, UNSW.

Institute for Culture \& Society, Western Sydney University.

Faculty of Law, UNSW. 


\section{Addressing Environmental Challenges 'From the Inside Out'}

A key challenge facing environmental law in the near-to-mediumterm future is the degree to which its effectiveness is constrained by its structural relationship to commercial law, and the related implications for legal professional services. In responding to environmental challenges through the medium of law, regulatory responses are limited by their secondary relationship to the internal structure of economic exchange: they effectively bolt environmental goals onto the edifice of commercial exchange as a protective afterthought. A more productive approach lies in reworking the tacit legal underpinnings of commercial activities. Creative use of commercial and transactional legal strategies has the potential to weave social and ecological values into the heart of exchange, and thus to address environmental law goals 'from the inside out'.

The primary genesis of this chapter is grounded in data collected between 2013 and 2015 in the Activism and Enterprise Project (the 'A\&E Project ${ }^{\prime}$ ) which was funded to explore the basic insight stated above. The A\&E project carried out primary empirical research into communitybased sustainability initiatives and grassroots innovations responding to climate change challenges, across a continuum from social activism to social enterprise. The purpose of the research was to explore the legal and regulatory frameworks that helped or hindered these innovative initiatives, a subset of which we are now calling SSEIs. The social significance of these initiatives was that they reconfigured economies and established alternatives to unsustainable practices. The capacity of SSEIs to make a positive contribution to the overall social fabric and to the building of resilient communities is related to how they negotiate life-cycle shifts: from vision to early experimentation and then to stable operation. These shifts are shaped in important ways by law and regulation.

A brief example of an SSEI can illustrate what is at stake. The Open Food Network (OFN), based in Melbourne, provides a digital platform and related services that link producers and consumers of local ethical food, enabling, as its website states 'farmers, eaters and independent food

4 Short-form for Australian Future Fellowship Award FT1 10100483 held by Professor Morgan for 'Between Social Enterprise and Social Movement: Responses to Climate Change at the Intersection of Rights and Regulation'. The support of the ARC for this work is gratefully acknowledged. 
enterprises to connect, trade, manage Food Hubs and coordinate logistics'. As a web-based platform that curtails the power of the middleman, OFN emphasises its desire to create positive social change of a systemic kind, one that will disrupt the existing dominance of large-scale commercial provision of food or housing. It has open-source principles at the centre of both its software and its human relations, designed to support small community groups anywhere in the world in setting up local initiatives easily and at low cost. However, OFN has struggled to source legal advice that helps it build an income stream flowing through its provision of a software platform while simultaneously protecting the inbuilt sociality and affordability of the practices of like-minded groups around the world in a collaborative community. Clear and affordable legal advice would greatly assist projects such as OFN to replicate horizontally, rather than scale up, and thus to expand the SSEI sector in a sustainable manner.

The growth of SSEIs is not easily defined as the emergence of a 'sector'. Drawing on the A\&E project as well as data from the International Comparative Social Enterprise Models (ICSEM) research project, ${ }^{5}$ we can say that SSEIs prioritise social relationships, some degree of economic democracy, interdependency and values other than economic efficiency and low costs, including but not limited to ecological values. They are a subset of social enterprise, and overlap with some aspects of the sharing economy: not the turbo-sharing economy of Airbnb and Uber, but smallerscale, more socially-oriented versions of these technologically innovative enterprises. But it is fair to say that the definition of an identifiable sector in this context remains diffuse. This is, in part, precisely because the legal, financial and organisational structures of our current economy do not sit comfortably with these types of initiatives. Therefore the very 'gap' that underpins the discussion presented here undermines their visibility. The suggestions for reform in this chapter are therefore intended to draw out the institutional potential of SSEIs and to improve the 'fit' between them and their larger ecosystem.

5 See emes.net/research-projects/social-enterprise/icsem-project/. Australia has a team participating in this international project, including two of the authors of this chapter. 


\section{Existing Pathways of Legal Support for SSEls}

There are three main sources of existing support.

A) First, some law firms provide advice to social enterprises, but most focus on not-for-profit and limited pro bono advice. Generally, law firms that provide professional legal services to the social enterprise sector in Australia are not easily identified as such without prior knowledge of personal contacts. Legal practitioners, particularly those in large urban areas, draw primarily on their existing commercial experience to provide advice on legal matters to social enterprises generally, and therefore to the SSEI subgroup also. This expertise tends to divide into not-for-profit and for-profit specialisms and experience. Most of these firms also offer pro bono services; however, the majority require the entity to be not-for-profit to be eligible to access these.

The recent advent of technology-enabled clearing houses designed to assist small businesses and start-ups to find relatively low-cost legal advice is potentially relevant to some SSEIs. These are being heralded as

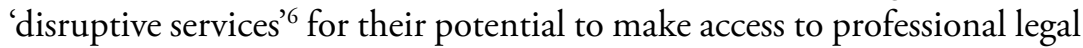
services easier and more affordable for small businesses. They typically use standard commercial documentation and the underlying assumptions of for-profit business models and legal structures.

Some smaller firms with more of a creative and hybrid focus are recently emerging. Clearpoint Counsel $^{7}$ is one example with a core focus on SSEI-relevant services. Branded as 'Legal Services. Reimagined. Simply', it offers 'holistic, collaborative and entrepreneurial services', stressing that 'we believe law should be a tool to empower you'. In addition to a variety of more traditional commercial advice, it offers specialist advice on 'social enterprise and sustainable economies law' as well as 'B Corporation Training and Certification'.

6 In Australia, examples include LawPath, LegalVision, LegalZoom, AdventBalance: see www. lawyersweekly.com.au/opinion/16286-legal-market-ripe-for-disruptive-innovation and the recent establishment of the Law Society project on the Future of Law and Innovation in the Profession (FLIP): www.law.unsw.edu.au/sites/law.unsw.edu.au/files/images/lib/future_of_legal_profession.pdf.

7 www.clearpointcounsel.com. 
B) Second, cognate initiatives have emerged to service social enterprise specifically and in some cases SSEIs. Some, such as Business Enterprise Centres, Justice Connect and Get Mutual provide services predominantly tied to specific legal forms (for-profit, not-for-profit and cooperatives respectively). These have limited use for SSEIs that seek to establish hybrid business models that draw on both profit and not-for-profit dimensions. Others, such as the Expert Advice Exchange of the NSW Government, a sub-initiative of the NSW Environmental Defenders' Office, Lex Mundi Pro Bono Foundation and the University of Melbourne Law School Sustainable Business Clinic, do serve hybrid initiatives but are all very small, specialised and embryonic. Overall, they privilege not-forprofit structures as the primary eligibility criterion, while more than half the social enterprises responding to two recent surveys in Australia had chosen for-profit or cooperative structures. ${ }^{8}$

C) Finally, social enterprise capacity-building programs broker select initiatives to access legal advice, sometimes at 'low-bono' fee levels, when needed.' These usually provide fairly general 'legal matters' style workshops or other material to groups of participants in a standard format, or 'template' style advice (e.g. on purchaser agreements, insurance arrangements or volunteer contracts). They sometimes also secure individualised legal support. But such support is only available to entities admitted to the program after a lengthy application process, and is often vulnerable to dispensing untimely or overly standard advice ill-suited to bespoke and/or complex arrangements.

In short, many of the existing avenues of support are shaped by assumptions of a divide between not-for-profit and for-profit legal structures which maps onto a related gulf between pro bono advice and expensive commercial advice. Moreover, while pro bono legal practitioners generally have access to well-developed networks, for those attempting to build their expertise and skills around working with social enterprises and SSEIs, there is no way, other than word of mouth, for them to identify each other or to expand opportunities to share knowledge and expertise.

8 ICSEM project, above $\mathrm{n} 5$ and Stephen Bennett et al, Legal Models Working Group Report (Social Innovation, Enterprise and Entrepreneurship Alliance, July 2014), www.employeeownership.com.au/ wp-content/uploads/2015/02/Legal-Models-Working-Group-Draft-Final-Report.pdf.

9 See, for example, National Pro Bono Resource Centre, Review of Parramatta City Council's Social Enterprise Pro Bono Legal Panel (2011), on file with second author. 


\section{Four Dimensions of an Effective Ecosystem of Professional Legal Support}

\section{A. Supporting legal practitioners to cultivate 'the touch'}

There is, then, a felt demand for a more extensive and effective ecosystem of professional legal support for small-scale initiatives that confound traditional distinctions between for-profit and not-for-profit economic activity. The key limitation of the existing pathways is an overarching unmet need that is challenging to convey succinctly. It can perhaps best be described as a culture fit with values prominent in the social enterprise sector and the SSEI subgroup, a 'contextual sensitivity' or, as described by one interviewee, 'the touch'. 'The touch' is grounded in a mix of shared values, especially economic democracy, community development, a holistic worldview and an understanding of how to meld social relationality with practical governance. It is partly experiential, embedded in tacit craft knowledge, and partly normative, linked to a set of ethical and political commitments, though not to any particular ideology.

By virtue of this elusive status, it is likely something that is best fostered in experiential peer to peer settings, particularly ones that link a network of both legal and non-legal professionals who are committed to the ethos involved. Such a network might have considerable value for legal professionals in both large firms and small firm or solo practice settings. For the former, it would provide professional development channels to help legitimise social enterprise generally and SSEI specifically as viable 'market segments'. For the latter, there is evidence that some working in this area identify themselves as 'corporate refugees' from 'war-torn law firms, battered and wanting to ... move away from negative, adversarial, competitive and risk-averse models of practising' ${ }^{10}$ There may also be opportunities to tap into technology-based networks that 'reduce the impediment of geographical distances' and create a 'virtual legal practice' which allows for small firms to aggregate work while simultaneously

10 Bronwen Morgan and Declan Kuch, The Sharing Economy: More than the Sum of its Parts? Implications for Legal Services (2014), Summary Report of Janelle Orsi Australia Workshop Series, UNSW LawSchool, www.activismandenterprise.weebly.com/uploads/2/2/3/2/22323902/140317_-orsi_aus_tour_unsw_writeup_-_final.pdf. 
allowing them to stay competitive in the marketplace. ${ }^{11}$ These can connect and support sole practitioners, such as Lawyer Mums Australia ${ }^{12}$ or clusters of 'dormant' legal practitioners, such as in Northern NSW, ${ }^{13}$ potentially interested in developing new and different practice streams.

\section{B. Introducing hybrid legal models for economic enterprises}

Legal forms matter too, however. SSEIs face intractable problems here in falling between traditional classifications of not-for-profit and for-profit. For the former, SSEIs typically generate and distribute earned income in ways quite different from standard charities. The latter may find the generic corporations template used by standard for-profit companies do not typically integrate SSEI-specific characteristics into the 'DNA' of the entity, nor protect them over the long term. Either way, a simplified choice of legal form that would allow trading, investment and income flows to supplement grant-based support and without adding undue organisational complexity, especially in relation to reporting, governance and tax status, would benefit SSEIs. It would also assist them in protecting their purpose and preventing private extraction of their assets as a result of changes of form, buy-outs or winding-up.

A range of innovations around hybrid legal structures are emerging that help to address these issues. ${ }^{14}$ Some of these are statutory legal models, such as the Community Interest Company in the UK that melds shareholder investment with an asset lock and capped dividends; or the Benefit Corporation structure in the US that enables directors to pursue a general public benefit without fear of shareholder retaliation. Other innovations offer special clauses such as the use of 'golden shares' to protect social mission; ${ }^{15}$ or model rules, adopted by voluntary choice of the entity, for modifying the constitution of a standard corporation,

11 Caroline Hart, 'Sustainable Regional, Rural and Remote Legal Practice in Queensland: The Importance of Innovation in Alliances and the Use of Information Technology' (2011) 16(1) Deakin Law Review 225, 252.

12 A Facebook group: see www.facebook.com/LawyerMumsAustralia/.

13 Morgan and Kuch, above n 10.

14 Bronwen Morgan, 'Transcending the Corporation: Social Enterprise, Cooperatives and Commons-Based Governance' in Thomas Clarke and Justin O'Brien (eds), The Oxford Handbook on the Corporation (Oxford University Press, in press).

15 Nick O'Donohoe and Simon Rowell, 'Going for Gold' (Big Society Capital, 2015), www. bigsocietycapital.com/sites/default/files/pdf/Golden\%20Share\%20Report.pdf. 
such as the Fair Shares model ${ }^{16}$ (which securely embeds social purpose and integrates founders, producers, employees, customers, service users and investors equally into core governance processes), and a voluntary certification version of the Benefit Corporation approach, a 'B-Corp' brand, in essence, that validates governance, transparency, environmental and social impact through third-party certification. However, none of these are in widespread use in Australia, although the B-Corp brand is gaining some traction.

\section{Adapting specific technical skill sets to the SSEl context}

While the existence of a hybrid legal form would assist in defining a distinctive legal site for SSEIs, they often encounter ongoing regulatory grey areas in trying to secure operational stability. Advice better suited to large-scale commercial operation tends to convey a reported 'fixation with legal impediments' ${ }^{17}$ and to fit poorly with SSEI culture. Pro bono advice is all too often 'off-the-shelf', overly complex and unwieldy for SSEI purposes and adds layers of unnecessary complexity to operations. While a sense of 'the touch' helps here, there are also technically distinctive aspects to SSEI operations. For example, ownership arrangements may include designing flat governance structures, protecting commitments to economic democracy, recognising 'sweat equity' returns, and structuring 'end of life' distributions that mix grant and investment income. Intellectual property issues may require expertise in open source and other commons-based forms of licensing, while employee contracts may systematically blur lines between staff and volunteers, and novel forms of land use, leasing and insurance relations often predominate.

This range of technical knowledge provides positive opportunities for the professional network suggested above to develop targeted seminars and training, potentially linked to continuing professional education and/or the development of new curricula in university degrees.

16 See www.fairshares.coop/.

17 Morgan and Kuch, above n 10. 


\section{Improving access}

The inaccessibility of legal advice is a centuries-old problem, but of bittersweet intensity here, given the potentially transformative ideals of SSEIs. Access can be improved both by enhancing relevance and reducing cost. A publicly available database of SSEI professionals from the network could encourage user-driven rankings and reviews to animate referrals and relevance. To stem the problem of one-size-fits all, overly didactic template advice, purpose-focused clusters within the network could deliver group-based training sessions to assist with the customisation of template advice. One-stop shops for particular sectors (e.g. food, energy) could develop referrals and partnerships between and beyond the legal profession. Clusters could also be geographically based, especially in regional areas, running local clinics covering a wide range of issues.

Since cluster-based strategies essentially allow 'bulk purchasing' of legal advice, they will help to reduce cost, opening up the possibility of widespread availability of 'low bono' services. These can be underpinned by, for example, transparency of costs charged on network sites, fee caps for particular types of advice, or retainers that include access to a specified quantity of advice within a given period. A broader cultural shift in expectations about what a typical private lawyer is entitled to earn is also part of this: ${ }^{18}$ perhaps 'community enterprise lawyer' could complement 'community legal centre' legal identities.

\section{Conclusion}

Overall two key reforms would assist in closing the gap in professional legal services for SSEIs in Australia: the establishment and promotion of hybrid legal models, whether statutory or self-regulatory, for enterprise activity; and the establishment and coordination of an SSEI-specific professional development network for legal practitioners and other key service providers. An effective professional network would prioritise 'the touch', break down divisions between not-for-profit/for-profit/cooperative legal status, facilitate 'trusted' partnering and/or referral between legal practitioners, widen access to and reduce the cost of legal services, and

18 RMIT Centre for Innovative Justice, Affordable Justice (2013) 48, mams.rmit.edu.au/ qr7u4uejwols1.pdf. 
NEW DIRECTIONS FOR LAW IN AUSTRALIA

develop clusters based on purpose and geography. While acknowledging the limits of purely legal reform in this area, we hope this discussion will catalyse a broader interest in cross-sectoral and multidisciplinary collaboration in the service of seeing the emerging Australian SSEI sector thrive. 
This text is taken from New Directions for Law in Australia: Essays in Contemporary Law Reform, edited by Ron Levy, Molly O’Brien, Simon Rice, Pauline Ridge and Margaret Thornton, published 2017 by ANU Press, The Australian National University, Canberra, Australia. 